\title{
Trickle-Down Technology and Screening of a Durable Goods Monopolist
}

\author{
Su-Chen Huang ${ }^{1}$, Shih-Ti Yu, ${ }^{2,}$, Woody Chih-Yi Chi ${ }^{3}$ and Wen-Ben Yang ${ }^{3}$ \\ ${ }^{1}$ Deparment of Finance, Overseas Chinese University, 100, ChiaoKwang Rd., Taichung 40721, Taiwan \\ R.O.C. \\ ${ }^{2}$ Department of Quantitative Finance, National Tsing Hua University, 101, Sec. 2, Kuang Fu Rd. Hsinchu 300, \\ Taiwan R.O.C. \\ ${ }^{3}$ Department of Finance, National Chung Hsing University, 250 KuoKuang Road, Taichung 402, Taiwan \\ R.O.C.
}

\begin{abstract}
We show that when it takes time for a durable goods monopolist to make its high-end new technology accessible to low-end market (the trickle-down technology constraint), the monopolist's high-end product might have a higher-than-optimum quality. This result differs from conventional screening models, in which the qualities of non-durable goods supplied by a monopolist never exceed the optimum, and only consumers with the highest valuation consume the efficient quality. In another literature discussing a durable goods monopolist who delays the introduction of low-end product as a marketing strategy, but not due to the trickle-down constraint, the qualities will not exceed the optimum either. Our results show that the trickle-down constraint will make the monopolist chooses a higher-than-optimum quality when the difference of the valuations of high demand and low demand consumers are in certain ranges. The intuition follows Spence (1975): the efficient quality is determined by the marginal cost and the average of all consumers' marginal valuations, while the monopolist chooses quality such that the marginal cost equals the marginal consumer's marginal valuation.
\end{abstract}

Keywords: Durable goods monopoly, Coase problem, trickle-down technology, screening.

\section{INTRODUCTION}

New technology is usually expensive and it takes time for manufacturers to make the technology trickled down to produce products more accessible to consumers. We often observe this phenomenon in the stereo industry. The first Super Audio Compact Disk (SACD) player made by Sony, SCD-1, sold for $\$ 5,000$ in 1999; in 2002 the cheapest of Sony's SACD players, SCDCE775, had a $\$ 250$ MSRP, while the SCD-1 continued to be Sony's flagship model. The electrostatic speaker manufacturer MartinLogan developed a technology trademarked Clear Spars for their Statement e2 speakers, which came to the market in 2000 with a list price of $\$ 80,000$ per pair. MartinLogan later applied the technology to their midprice (\$3,300 per pair) Aeon i in 2003. The amplifier manufacturer Conrad-Johnson introduced in 2000 its top pre-amplifier, ART Series 2, and in 2003 added to their product line a stripped-down version of the ART, the Premier 17LS, whose price is less than one-third the price of the ART. For cameras, Sony introduced in 2008 its flagship digital camera DSLR $\alpha-900$ for $\$ 3,000$, and one year later DSLR $\alpha-850$, which has

\footnotetext{
*Address correspondence to this author at the Department of Quantitative Finance, National Tsing Hua University, 101, Sec. 2, Kuang Fu Rd. Hsinchu 300, Taiwan R.O.C.; Tel: +886-3-5715131, Ext 62130; Fax: +886-3-5621823; E-mail: styu@mx.nthu.edu.tw
}

smaller viewfinder coverage, was available for $\$ 2,000$. Similarly in the automobile industry, the four-wheeldrive vehicle manufacturer Land Rover introduced their mid-price model Discovery in 1986, after they remodelled their luxury line Range Rover in the early 80 s.

In these examples, before the firms could scale down their new technologies for the mass markets, they sold only the high-end products; and after the more affordable low-end products became available, they sold both kinds of products. Furthermore, these products are durable goods, and so by the time the firms introduced the low-end products, the consumers who had bought the high-end products were no longer in the market. If we abstract from the interfirm competition by assuming that the durable goods market is monopoly, then there are both screening (seconddegree price discrimination) and intertemporal price discrimination in these cases. (See Zevgolis and Fotis 2014 for related issues in parallel imports.)

In the second-degree price discrimination models, where a monopolist can use several quality-price packages to screen consumers, it is well known that a monopolist would discriminate the consumers by offering the efficient quality only to the consumer with the highest valuation, and offering everyone else a quality less than the optimum. In no circumstances 
could the consumers get above-optimum quality in the static model (see Mussa and Rosen 1978; Maskin and Riley 1984).

In this paper we would show that the qualities of the high-end products might exceed the social optimum, which cannot happen in the screening models. We use Bulow's (1982) two-period framework. The monopolist introduces the high-end product in the first period. It cannot produce the low-end version until the second period, which we call the trickle-down technology constraint. There are two types of consumers: the snob and the normal type. The snob type has stronger demand for quality than the normal. In addition to screening the two types by offering two quality-price packages (second-degree price discrimination), the monopolist can do intertemporal price discrimination by selling the high-end product at a lower price in the second period. However these two kinds of price discriminations affect the monopolist's profit differently. The second-degree price discrimination increases the profit, but the intertemporal one hurts the monopolist, as Coase (1972) conjectures.

The qualities of durable goods made by a monopolist are related with the monopolist's concern to counter the Coase problem. Since the monopolist usually cannot commit not to cut down prices in the future, some high-demand consumers will postpone their purchases and this reduces the monopolist's profit. Bulow (1986) and Waldman (1996) show that the monopolist can reduce the durability of its product, so that there are more demand in the future to support the price, and hence the durability is lower than the optimum. However, Kinokuni, Ohkawa, and Okamura (2010) show that if the durability is affected by both the built-in durability and consumers' maintenance, the monopolist might increase the built-in durability to a higher level than the optimum. Another strategy the monopolist can use to support prices is to introduce a better product to replace the first product. Levinthal and Purohit (1989) study the case. They focus on the timing of introducing the new product, the pricing, and the use of buyback policy, but assume that the quality difference between the two generations' products is an exogenous variable. Fudenberg and Tirole (1998) use a very general framework to study product upgrades and the related marketing practices- tradeins and buybacks, but they too treat the qualities as exogenous variables.

The intuition why the monopolist chooses qualities higher than the optimum is from Spence's (1975) static model, in which Spence shows that the quality is optimum when the average of all consumers' marginal benefits equals the marginal cost, while a monopolist will set the marginal consumer's marginal benefit equal to the marginal cost. The monopoly's quality could be higher or lower than the optimum, depending on the demand conditions. In particular, for a linear demand, the quality chosen by the monopolist is the same as the optimum.

Chi (1999) discusses the quality choice of a durable goods monopolist who decides the quality of its product in the first period, and continues selling it in the second period. To attract high-demand consumers to purchase early, even though they know that the price will be lower later, the monopolist choose a quality at least as high as the optimum, and higher than the optimum when the discount factor is small.

Chi and $\mathrm{Wu}$ (2006) consider the case where there is a continuum of consumers whose valuation for quality varies. The monopolist also faces the trickle-down production constraint; it sells the high-end product in the first periods and sells both the high-end and the low-end products in the second period. In the equilibrium, both products' qualities are higher than the optimum. In this paper, we assume that there are only two types of consumers, and get the result that the quality of the high-end product some times exceeds the optimum, and sometimes is lower than the optimum.

The interaction of the two price discriminations could also affect the standard screening results in a different way. Inderst (2008) considers a durable goods monopolist who can offer various qualities in each period to two types of consumers, and finds that the monopolist might sell at a loss to the low demand consumers, which will not happen in static screening model.

Sometimes a firm is able to produce both high-end and low-end products from the beginning but decides not to. Publishers do not print paperbacks of new books until they have sold the hardcovers for some time. Some fashion designers offer mid-price lines of their clothes after they have established their brand names. Wilson and Norton (1989) focus on the timing for introducing the lower-quality product, and do not discuss how the firm chooses prices or qualities. Moorthy and Png (1992) consider a monopolist who faces two types of consumers (high-demand and lowdemand) and is able to introduce high and low qualities simultaneously. In some cases, the monopolist prefers 
sequential introduction: high-end product in the first period and low-end in the second. However, the qualities do not exceed the optimum in any equilibrium. Wang (2000) also uses a model with two types of consumers, and shows that when the monopolist is able to offer two quality-price packages each period, the result is the same as static quality discrimination. Therefore, no qualities can be higher than the optimum.

Our paper is organized as follows. Section 2 describes the model and derives the social optimum qualities. Section 3 solves the qualities in the screening equilibrium, and compares the qualities with the optimum. Section 4 concludes.

\section{THE MODEL}

We use Bulow's (1982) two-period framework. A monopolist faces two types of consumers, the snob (type- $s$ ) and the normal (type- $n$ ). The snob consumers have stronger demand for quality than the normal. The monopolist cannot tell who is who, and knows that the probability of a consumer being a snob is $\lambda$. At the start of period 1, the monopolist introduces a new product $H$ with quality $q_{H}$ at price $p_{1}$. The quality is a public information. The monopolist produces $H$ after it gets orders from consumers. The product is perfectly durable and those who purchase it in period 1 is able to enjoy it in period 2 . The monopolist has to wait till the start of period 2 to introduce a lower-cost version of product $H$, due to the constraint that it takes time to make the technology trickled down, which we call the tricked-down constraint. We call the second product $L$ and denote its quality and price as $q_{L}$ and $r$ respectively. The monopolist can continue selling $H$ in the second period at price $p_{2}$. So in period 2 the monopolist has to decide whether to introduce $L$ and whether to continue selling $H$. The monopolist and the consumers have the same discount factor $\delta$. The per unit cost of a product with quality $q_{i}$ is $\mathrm{c}\left(q_{i}\right)=q_{i}^{2} / 2, i=$ $H, L$. For simplicity we assume that there is no fixed cost.

The total discounted surplus of a consumer who purchases $H$ in period 1 at price $p_{1}$ is

$U_{i}\left(q_{H}, p_{1}\right)=(1+\delta) \theta_{i} q_{H}-p_{1}, \quad i=s, n$

where $\delta \in(0,1)$ is the discount factor, and $\theta_{i}$ is the demand parameter of type- $i$ consumer; $\theta_{s}>\theta_{n}$. A consumer's discounted surplus from buying $H$ in period 2 is
$U_{i}\left(q_{H}, p_{2}\right)=\delta\left(\theta_{i} q_{H}-p_{2}\right), \quad i=s, n$

and is

$U_{i}\left(q_{L}, r\right)=\delta\left(\theta_{i} q_{L}-r\right), \quad i=s, n$

from buying $L$. The reservational utility is 0 for every consumer. We assume that if they get the same surplus from purchasing and not purchasing, then they will purchase.

\subsection{The Social Optimum}

At the social optimum, both products, if produced, should be sold at the marginal cost. There are four possibilities: (1) both types of consumers purchase $H$ in period 1 ; (2) none purchases $H$ in period 1 , and both purchase $L$ in period 2; (3) the snob purchase $H$ in period 1, and the normal purchase $H$ in period 2; (4) the snob purchase $H$ in period 1 , and the normal purchase $L$ in period 2. Case (3) cannot be optimal, because if the normal is able to purchase $H$ at the marginal cost, then they should have bought it in period 1. Case (2) is dominated by case (1). So we are left with cases (1) and (4). The social welfare function in case (1) is

$W_{H, s n}=(1+\delta)\left[\lambda \theta_{s}+(1-\lambda) \theta_{n}\right] q_{H}-q_{H}^{2} / 2$,

where the subscript sn denotes the two types of consumers. Maximizing $W_{H, s n}$ over $q_{H}$, subject to the constraint that the normal type gets positive surplus from consuming $H$ :

$(1+\delta) \theta_{n} q_{H}-q_{H}^{2} / 2 \geq 0$

we get

$q_{H, s n}^{*}=(1+\delta)\left[\lambda \theta_{s}+(1-\lambda) \theta_{n}\right]$,

and

$W_{H, s n}^{*}=(1+\delta)^{2}\left[\lambda \theta_{s}+(1-\lambda) \theta_{n}\right]^{2} / 2$

provided that $\theta_{s} / \theta_{n}<(1+\lambda) / \lambda$.

The social welfare function in case (4) is

$W_{H L}=\lambda\left[(1+\delta) \theta_{s} q_{H}-q_{H}^{2} / 2\right]+(1-\lambda) \delta\left(\theta_{n} q_{L}-q_{L}^{2} / 2\right)$

Maximizing $W_{H L}$ over $q_{H}$ and $q_{L}$, we get

$q_{H, s}^{*}=(1+\delta) \theta_{s}$, and $q_{L}^{*}=\theta_{n} ;$

Hence

$W_{H L}^{*}=\lambda\left[(1+\delta) \theta_{s}\right]^{2} / 2+(1-\lambda) \delta \theta_{n}^{2} / 2$ 
Denote by $\mathrm{X}$ the ratio $\theta_{s} / \theta_{n}$. Comparing $W_{H, s n}^{*}$ with $W_{H L}^{*}$, we get the next proposition for the optimal qualities. Let

$$
X_{1}=1+\frac{\sqrt{1+\delta+\delta^{2}}}{\sqrt{\lambda}(1-\delta)},
$$

which is less than $(1+\lambda) / \lambda$.

Proposition 1. When $X \equiv \theta_{s} / \theta_{n}<X_{1}$, the social optimum is to produce $H$ with quality $q_{H, s n}^{*}=(1+\delta)\left[\lambda \theta_{s}+(1-\lambda) \theta_{n}\right]$, purchased by both types of consumers in period 1. When $X>X_{1}$, the optimum is to produce $H$ with quality $q_{H, s}^{*}=(1+\delta) \theta_{s}$ and only the snob consumers consume in period 1 , and to produce $L$ in period 2 with quality $q_{L}^{*}=\theta_{n}$, consumed by the normal consumers.

When the two types' valuations for quality are close, the social optimum is to produce $H$ only, and the optimal quality is determined by equating the marginal cost to the average of their marginal valuations. When their valuations are very different, $X \geq X_{1}$, the normal type cannot purchase $H$ in period 1 , even though it is priced at marginal cost. To serve the normal type in period 2, since we assume there is no fixed cost of producing $L$, the social welfare is larger when the normal type can consume a product that is tailor-made for them.

\subsection{The Commitment Case}

As a benchmark, we consider the case where the monopolist is able to commit himself in period 1 to his period-2 choices, including: $p_{2}$; whether to introduce $L$, and if so, the quality and the price of $L$. Of these commitments, Bulow (1982) shows that the monopolist's profit is lower if it continues selling the same product, so selling nothing is better than selling $H$ in period 2. Therefore when the monopolist can commit, it will commit to selling only $L$ or nothing in period 2.

If the monopolist commits to selling $L$ in period 2 , it wants the snob consumers to purchase in period 1 . The monopolist can commit to the strategy: offering $\left\{q_{H}=(1+\delta) \theta_{s}, p_{1}=q_{H}^{2}\right\}$ in period 1 ; if $H$ is sold, then offers $L$ in period 2 , otherwise shutting down the market in period 2. The normal consumes will not purchase $H$. The snob consumers get 0 surplus from consuming $\mathrm{H}$. If they do not purchase $H$, no product will be available in period 2, and they still get 0 surplus. Therefore they purchase $H$. The monopolist can get profit (the superscript denotes commitment)
$\prod_{H L}^{C_{0}}=\lambda(1+\delta)^{2} \theta_{s}^{2} / 2+\delta \lambda \theta_{n}^{2} / 2$

If the monopolist commits to shutting down the market in period 2, it will set $p_{1}$ equal to the maximal price that the normal consumers accept: $p_{1}=(1+\delta) \theta_{n} q_{H}$, , and so the quality is

$q_{H, s n}^{C_{0}}=(1+\delta) \theta_{n}$

The profit from the strategy is

$\prod_{H, s n}^{C_{0}}=(1+\delta)^{2} \theta_{n}^{2} / 2$.

Comparing the two profits, we get:

$\prod_{H L}^{C_{0}}>(=,<) \prod_{s n}^{C_{0}} \quad$ if $X>(=,<) X_{C_{0}}$,

where

$X_{C_{0}}=\frac{\sqrt{1+\delta+\delta^{2}+\lambda \delta}}{\sqrt{\lambda}(1+\delta)}$

and $1<X_{C_{0}}<X_{1}$.

We summarize the monopolist's strategy when it can commit in the next lemma.

Lemma 1. When the monopolist can commit to its actions in period 2 , it will

(1) sell $H$ to both types in period 1 with the quality $q_{H, s n}^{C}=(1+\delta) \theta_{n}$, , when $1<X \leq X_{C_{0}}$;

(2) sell $H$ to the snob consumers in period 1 with the quality $q_{H, s}^{C}=(1+\delta) \theta_{s}$, and sell $L$ to the normal consumers with the quality $\theta_{n}$ in period 2 , when $X \geq X_{C_{0}}$.

Next we compare the qualities of the commitment outcome with the optimum.

Proposition 2. Suppose that the monopolist can commit to its actions in period 2 , then

(1) when $X<X_{C_{0}}$, the variety of products is the same as the optimum but the quality of $H$ is less than the optimum;

(2) when $X_{C_{0}} \leq X<X_{1}$, the quality of $H$ is higher than the optimum, and the monopolist offers more varieties of product than the optimum;

(3) when $X \geq X_{1}$, the varieties of products, the qualities of $H$ and $L$ are all optimal. 
In this screening problem, we assume the monopolist can commit, and therefore the Coase problem is not present. The monopolist cannot introduce two products in the first period due to the trickled-down constraint. The standard screening equilibrium is that the monopolist sells effcient $q_{H}$ to the snob consumers and a less-than-optimum $q_{L}$ to the normal consumers. Here we see that when $X$ is small, screening is not maximizing profit, and both the optimum and the monopolist's strategy are to serve both types of consumers in period 1 with product $H$. As in Spence (1975), the monopolist equates the marginal valuation of the marginal consumer $\left(\theta_{n}\right)$ to the marginal cost, while the optimum equates the average of both types' marginal valuation. Hence the monopolist chooses a lower quality than the optima. When $X$ is larger, there is a range of $X$ in which the optimum is to sell only $H$ to both types of consumers, but the monopolist will screen the consumers by introducing $L$ in the second period. The monopolist sets quality $q_{H}$ higher than the optimum. When $X$ is even higher that the optimum is to sell $H$ to the snob consumers only, the quality of $H$ in the commitment equilibrium is the same as the optimum.

\section{THE EQUILIBRIUM WITHOUT COMMITMENT}

We now assume that the monopolist cannot commit to its period-2 actions, and has to deal with the Coase problem. The possible strategies the monopolist might choose include: (1) selling $H$ to both in period 1, and no sale in period 2; (2) selling $H$ to the snob consumers in period 1 and $L$ to the normal consumers in period 2, (3) selling $H$ to the snob consumers and $L$ to the normal consumers; and (4) selling nothing in period 1, and sell to both or only one type of consumers in period 2 . Since the snob consumers have higher valuation than the normal consumers, strategy (3) cannot be an equilibrium. Strategy (4) cannot be an equilibrium either, because the monopolist can get a higher profit by selling $H$ in period 1 . So we are left with the first two strategies.

Selling $\boldsymbol{H}$ in period 1 and $L$ in period 2 Suppose that the monopolist offers $q_{H}$ and $p_{1}$. We need to analyze what would happen if the snob consumers refuse to purchase $H$. Following this path, the monopolist's period-2 strategy is to sell (a) $H$ to both, (b) $H$ to the snob and $L$ to the normal, (c) $L$ to both, or (d) $L$ to the snob and nothing to the normal. If the monopolist sells $H$ to both, the price is $p_{2}=\theta_{n} q_{H}$, and the profit is

$\pi^{a}=\theta_{n} q_{H}-q_{H}^{2} / 2$.

For strategy $b$, the monopolist solves the problem:

$\max _{q_{L}, p_{2}, r} \lambda\left(p_{2}-q_{H}^{2} / 2\right)+(1-\lambda)\left(r-q_{L}^{2} / 2\right)$
Subject to

$\theta_{s} q_{H}-p_{2} \geq \theta_{s} q_{L}-r$

$\theta_{n} q_{L}-r \geq 0$.

Setting both constraints as equality and maximizing over $q_{L}$, we get the profit as

$\pi^{b}=\lambda\left(\theta_{s} q_{H}-q_{H}^{2} / 2\right)+(1-\lambda)\left[\theta_{n}-\lambda\left(\theta_{s}-\theta_{n}\right) /(1-\lambda)^{2}\right]$, if $X<1 / \lambda$.

If the monopolist sells $L$ to both types, the profit is

$\pi^{c}=\theta_{n}^{2} / 2$

If then the monopolist want to sell $L$ to the snob consumers only, the quality is $q_{L}=\theta_{s}$, the price $r=\theta_{s}^{2}$, and the profit

$\pi^{d}=\lambda \theta_{s}^{2} / 2$

We need to rank the four profits to know the monopolist's optimal strategy after no one purchases $H$ in period 1. If the monopolist serves both types with the same product in period 2 , it will get a higher profit from selling $L$ than $H$ to both, for $q_{L}$ can be adjusted but $q_{H}$ not. Therefore $\pi^{c} \geq \pi^{a}$. Next, we see that $\pi^{d} \geq \pi^{c}$ if $\theta_{s}^{2}>\theta_{n}^{2} / \lambda$, or $X>1 / \sqrt{\lambda}$. Since $1 / \lambda>1 / \sqrt{\lambda}$, the monopolist will choose strategy $d$ and the snob consumers get 0 surplus when $X>1 / \lambda$.

If $1 / \sqrt{\lambda}<X<1 / \lambda$, either strategy $b$ or $d$ would be chosen. If $1<X<1 / \sqrt{\lambda}$, either $b$ or $c$ would be chosen. Let $u_{s}^{i}, i=b, c, d$, be the snob's surplus when the monopolist adopts strategy $b, c$, and $d$. Then

$$
u_{s}^{b}=\left(\theta_{s}-\theta_{n}\right)\left(\theta_{n}-\lambda \theta_{s}\right) /(1-\lambda), u_{s}^{c}=\left(\theta_{s}-\theta_{n}\right) \theta_{n} \text {, and } u_{s}^{d}=0 \text {. }
$$

In period $1, q_{H}$ and $p_{1}$ need to satisfy the incentive constraint so that the snob consumers purchase $\mathrm{H}$ :

$(1+\delta) \theta_{s} q_{H}-p_{1} \geq \delta u_{s}^{i}$,

where $i=b, c$, or $d$. If (16) is satisfied, then the snob consumers purchase $H$ in period 1 , and in period 2 the monopolist sells $L$ to the normal consumers with the quality $q_{L}=\theta_{n}$, price $r=\theta_{n}^{2}$, and gets profit $\pi_{L}=\theta_{n}^{2} / 2$. Setting the constraint (16) as equality, The monopolist's period-1 problem is

$$
\max _{q_{H}} \lambda\left[(1+\delta) \theta_{s}-q_{H}^{2} / 2\right]-\delta \lambda u_{s}^{i}+\delta(1-\lambda) \theta_{n}^{2} / 2
$$

Since $u_{s}^{i}$ is independent of $q_{H}$, we get $q_{H}=(1+\delta) \theta_{s}$

$$
\text { Let } y=(1-\sqrt{\lambda})^{2} /(1-\lambda) \text {, }
$$




$$
X_{b c}=\frac{2-\sqrt{(1-\lambda)\left[-1+\lambda+\delta^{2}(1+\lambda)\right] / \lambda}}{1+\lambda-\delta^{2}(1-\lambda)}
$$

and

$X_{b d}=\frac{2-\delta \sqrt{2(1-\lambda) / \lambda}}{2 \lambda-\delta^{2}(1-\lambda)}$

We summarise the monopolist's optimal strategy in period 2 after no one purchases $H$ in period 2 and its total profit:

Lemma 2. Suppose that the monopolist offers $H$ in period 1 with quality $q_{H}=(1+\delta) \theta_{s}$. If no one purchases $H$ in period 1 , the monopolist's reaction will depend on $\delta, \lambda$, and $X$ in the following ways:

(1) the monopolist chooses $d$ if $X \geq 1 / \lambda$;

(2) when $\lambda>1 / 2$ and $\delta^{2} \in[(1-\lambda) / \lambda, 1)$, it chooses strategy $b$ if $X<1 / \sqrt{\lambda}$, and $d$ if $X \geq 1 / \sqrt{\lambda}$

(3) when $\delta^{2} \in(2 y,(1-\lambda) / \lambda]$, it chooses strategy $b$ if $X<X_{b c}, c$ if $X \in\left[X_{b c}, 1 / \sqrt{\lambda}\right)$, and $d$ if $X \geq 1 / \sqrt{\lambda}$;

(4) when $\delta^{2}<2 y$, it chooses strategy $b$ if $X<X_{b d}$, and $d$ if $X \geq X_{b d}$.

Lemma 3: The monopolist sets $p_{1}=(1+\delta)^{2} \theta_{s}^{2}-\delta u_{s}^{i}$ when strategy $i$ applies after no one accepts $p_{1}, i=b, c$, $d$. The total profit is

$$
\begin{aligned}
& \prod_{H L}^{i}=\lambda(1+\delta)^{2} \theta_{s}^{2} / 2-\delta \lambda u_{s}^{i}+\delta(1-\lambda) \theta_{n}^{2} / 2, \\
& i=b, c, o r, d .
\end{aligned}
$$

Note that $\prod_{H L}^{d}=\prod_{H L}^{C_{0}}$, the profit when the monopolist can commit and sells $H$ in period 1 and $L$ in period 2.

Selling $\boldsymbol{H}$ to all consumers in period 1 Suppose that the monopolist offers $q_{H}$ at price $p_{1}$ such that

$$
(1+\delta) \theta_{n} q_{H}-p_{1} \geq 0
$$

Then the normal consumers will purchase $H$, for they always get 0 surplus in period 2 . If the snob consumers do not purchase, then they reveal their type as well and will get 0 surplus in period 2 . So both types of consumers purchase.

$$
\text { Let } P_{1}=(1+\delta) \theta_{n} q_{H} \text {, and solve }
$$

$$
\max _{q_{H}}(1+\delta) \theta_{n} q_{H}-q_{H}^{2} / 2
$$

We get

$$
q_{H, s n}^{E}=(1+\delta) \theta_{n}
$$

$P_{1}=(1+\delta)^{2} \theta_{n}^{2}$, and

$\prod_{H, s n}^{E}=(1+\delta)^{2} \theta_{n}^{2} / 2$

Note that $\Pi_{s n}^{E}=\Pi_{s n}^{C o}$, the profit when the monopolist can commit and sells only $H$.

Since the profit in the screening equilibrium $\prod_{H L}^{i}$ increases with $X$, but $\prod_{H, s n}^{E}$ is constant with $\mathrm{X}$, there exist critical value of $X$ that the two profits are equal. Let the values be $X_{i}, i=b, c, d$, then

$\prod_{H L}^{i}<,(=,>) \prod_{H, s n}^{E}$ if $X<,(=,>) X_{i}, i=b, c, d$.

Where $X_{d}=X_{C_{0}}$ in (15),

$X_{b}=\frac{\delta(1+\lambda)+\sqrt{\delta \lambda(1-\lambda)\left[\delta^{3}(1-\lambda)+\delta(1+\delta)(1-\lambda)(3+\delta)+1-2 \lambda-\lambda^{2}\right]}}{\lambda\left[(1+\delta)^{2}-\lambda\left(1+\delta^{2}\right)\right]}$

And

$X_{C}=\frac{\delta \lambda+\sqrt{\delta^{2} \lambda^{2}+\lambda(1+\delta)^{2}\left(1+\delta+\delta^{2}-\delta \lambda\right)}}{\lambda(1+\delta)^{2}}$

Since $X_{C_{0}}=X_{d}<X_{b}<X_{c}<X_{1}$, and we focus on whether the quality of $H$ can be higher than optimum, we present our main result as follows:

Proposition 3. When the monopolist cannot commit, depending on the parameters $\delta$ and $\lambda$, it sells $H$ to both types of consumers when $X<\hat{X}$, where $\hat{X}$ could be $X_{b}, X_{c}$, or $X_{d}$.

Furthermore,

(1) it starts screening consumers at a value of $X$ that is at least as large as when it can commit: $\hat{X} \geq X_{C_{0}}$

(2) when $X<\hat{X}$, the variety of products is the same as the optimum but the quality of $H$ is less than the optimum;

(3) when $\hat{X} \leq X<X_{1}$, the quality of $H$ is higher than the optimum, and the monopolist offers more varieties of product than the optimum;

(4) when $X \geq X_{1}$, the varieties of products, the qualities of $H$ and $L$ are all optimal. 
When the monopolist cannot commit, it needs to leave some surplus to the snob consumers. Therefore the maximal profit from screening is less than or equal to when it can commit, and it takes a larger $X$ for screening to get higher profit than no screening. Still, as in the case where the monopolist can commit, the quality of $H$ could be less than, equal to, or higher than the optimum.

\section{CONCLUSION}

When a monopolist has a technology to produce a new durable good with good quality at a high cost, consumers would expect that a cheaper variant could be available later. Sometimes the monopolist is able to produce a cheaper variant from the beginning but chooses not to. Wang (2000) considers the case and gets the standard result of the screening model; namely, the high demand consumers get efficient qualities, while the other consumers get lower-thanefficient qualities.

We consider the case that the monopolist is not able to do it until some time later. We find that the monopolist might produce its first product with a quality lower than the optimum when the difference of the valuations of the two types of consumers $(X)$ is small, higher than the optimum when $X$ is in the middle range, and equal to the optimum when $X$ is large.

Compared with the optimum, when $X$ is small $(X<\hat{X})$ the consumers are worse off because they consume a lower-than-optimum quality; when $\hat{X} \leq X<X_{1}$, the consumers are worse off because the snob consumers consume a higher-than-optimum quality while the normal consumers cannot consume in the first period and are only able to consume the lowend product; when $X$ is large that the two types of consumers should consume different products at the optimum, the monopolist provides the efficient qualities but sells at higher prices. There are deadweight losses in the first two cases, but no deadweight losses in the last case, because both the qualities and the quantities are optimal. However, since identifying the optimum in the real world is not easy, it would be difficult for a government to intervene.

\section{REFERENCES}

Bulow, J. 1982. "Durable Goods Monopolists." Journal of Political Economy. 90: 314-332. http://dx.doi.org/10.1086/261058

Bulow, J. 1986. "An Economic Theory of Planned Obsolescence." Quarterly Journal of Economics. 101: 729-750. http://dx.doi.org/10.2307/1884176

Chi, C.Y. 1999. "Quality Choice and the Coase Problem." Economics Letters, 64: 107-115. http://dx.doi.org/10.1016/S0165-1765(99)00067-1

Chi, C.Y. and S. Wu. 2006. "Intertemporal Quality Discrimination of a Durable Good Monopolist." Economics Letters. 92: 184-191. http://dx.doi.org/10.1016/j.econlet.2006.01.032

Fudenberg, D. and J. Tirole. 1998. "Trade-Ins, Upgrades, and BuyBacks." Rand Journal of Economics. 29: 235-258. http://dx.doi.org/10.2307/2555887

Inderst, R. 2008. "Durable Goods with Quality Differentiation." Economics Letters. 100: 173-177. http://dx.doi.org/10.1016/j.econlet.2008.01.006

Kinokuni, H., T. Ohkawa, and M. Okamura. 2010. "Planned Antiobsolescense Occurs When Consumers Engage in Maintenance." International Journal of Industrial Organization. 28: 441-450. http://dx.doi.org/10.1016/j.ijindorg.2009.10.008

Levinthal, D. and D. Purohit. 1989. "Durable Goods and Product Obsolescence." Marketing Science. 8: 35-56. http://dx.doi.org/10.1287/mksc.8.1.35

Maskin, E. and J. Riley. 1984. "Monopoly with Incomplete Information." Rand Journal of Economics. 15: 171-196. http://www.jstor.org/stable/2555674

Moorthy, K.S. and I.P.L. Png. 1992. "Market Segmentation, Cannibalization, and the Timing of Product Introduction." Management Science. 38: 345-359. http://dx.doi.org/10.1287/mnsc.38.3.345

Mussa, M. and S. Rosen. 1978. "Monopoly and Product Quality." Journal of Economic Theory. 18: 301-317. http://dx.doi.org/10.1016/0022-0531(78)90085-6

Spence, M. 1975. "Monopoly, Quality and Regulation." Bell Journal of Economics. 6: 156-169. http://dx.doi.org/10.2307/3003237

Waldman, M. 1996. "Durable Goods Pricing When Quality Matters." Journal of Business. 69: 489-510. http://dx.doi.org/10.1086/209702

Wang, R. 2002. "Optimal Pricing Strategy for Durable-Goods Monopoly." Journal of Economic Dynamics and Control. 25: 789-804. http://dx.doi.org/10.1016/S0165-1889(00)00041-5

Wilson, L.O. and J.A. Norton. 1989, "Optimal Entry Timing for a Product Line Extension." Marketing Science. 8: 1-17. http://dx.doi.org/10.1287/mksc.8.1.1

Zevgolis, Nikolaos E. and Panagiotis N. Fotis. 2014. "Prohibition of Parallel Imports as a Vertical Restraint: per se Approach or a Misunderstanding?" European Journal of Law and Economics. 38: 317-342. http://dx.doi.org/10.1007/s10657-012-9315-6

Received on 06-02-2015

Accepted on 24-03-2015

Published on 16-04-2015

DOI: http://dx.doi.org/10.6000/1929-7092.2015.04.06

(c) 2015 Huang et al.; Licensee Lifescience Global.

This is an open access article licensed under the terms of the Creative Commons Attribution Non-Commercial License (http://creativecommons.org/licenses/by-nc/3.0/) which permits unrestricted, non-commercial use, distribution and reproduction in any medium, provided the work is properly cited. 